\title{
EVI1 promotes epithelial-to-mesenchymal transition, cancer stem cell features and chemo-/radioresistance in nasopharyngeal carcinoma
}

Yaoyong Lu ${ }^{1+}$, Yingying Liang ${ }^{2 \dagger}$, Xin Zheng $^{3+}$, Xubin Deng ${ }^{2^{*}}$, Wendong Huang ${ }^{4^{*}}$ and Gong Zhang ${ }^{5^{*}}$

\begin{abstract}
Background: Aberrant EVI1 expression is frequently reported in cancer studies; however, its role in nasopharyngeal carcinoma (NPC) has not been examined in detail. The aim of the present study is to investigate the involvement of EVI1 in progression and prognosis of NPC.

Methods: RT-PCR, immunohistochemistry and western blot assays were used to examine the expression of EVI1 in NPC tissues and cell lines. Fluorescence in situ hybridization assay was used to examine the amplification of EVI1 in NPC tissues. The biological effect of EVI1 was determined by both in vitro and in vivo studies. The dual-luciferase reporter assay was performed to confirm that EVI1 bind at E-cadherin and $\beta$-catenin promoters. The ChIP, EMSA, and coimmunoprecipitation combined with mass spectrometry assays were used to analyze the EVI1 regulated proteins.

Results: EVI1 expression level was up-regulated in NPC tissues and cell lines. EVI1 was amplificated in NPC tissues. We observed that EVI1 down-regulation decreased the cell proliferation and invasive capacity of NPC cells in vitro and in vivo. EVI1, snail, and HDAC1 formed a co-repressor complex to repress E-cadherin expression and ultimately contributed to epithelial mesenchymal transition (EMT) phenotype in NPC cells. In another way, EVI 1 directly bound at $\beta$-catenin promoter and activated its expression. $\beta$-catenin mediated EVI1's function on cancer stem cells (CSCs) properties. EVI1 up-regulation predicted unfavorable prognosis and contributed to chemo/radio-resistance in NPC cells. Finally, we constructed arsenic trioxide-loaded nanoparticles (ALNPs) and revealed that ALNPs exerted antitumor effect in NPC cells.
\end{abstract}

Conclusions: Our data indicated that EVI1 played an oncogenic role in NPC growth and metastasis and that EVI1 might serve as a novel molecular target for the treatment of NPC.

Keywords: EVI1, Epithelial mesenchymal transition, Cancer stem cells, Nasopharyngeal carcinoma

\footnotetext{
*Correspondence: xubindeng@126.com; wendonghuang@126.com; zhanggong7446@163.com

†Yaoyong Lu, Yingying Liang and Xin Zheng contributed equally to this work.

${ }^{2}$ Affiliated Cancer Hospital \& Institute of Guangzhou Medical University, Guangzhou, China

${ }^{4}$ Department of Pharmacy, Maoming People's Hospital, Maoming, Guangdong, China

${ }^{5}$ Department of Radiotherapy, People's Hospital of Shanxi Province, Taiyuan, China

Full list of author information is available at the end of the article
}

(c) The Author(s). 2019 Open Access This article is distributed under the terms of the Creative Commons Attribution 4.0 International License (http://creativecommons.org/licenses/by/4.0/), which permits unrestricted use, distribution, and reproduction in any medium, provided you give appropriate credit to the original author(s) and the source, provide a link to the Creative Commons license, and indicate if changes were made. The Creative Commons Public Domain Dedication waiver (http://creativecommons.org/publicdomain/zero/1.0/) applies to the data made available in this article, unless otherwise stated. 


\section{Background}

Nasopharyngeal carcinoma (NPC), which arises from nasopharyngeal epithelial cells, is highly prevalent in East Asia, especially in southern China. Epstein-Barr virus (EBV) exposure, diet and genetic factors together contribute to NPC initiation. NPC has the potential to metastasize to cervical lymph nodes or distant organs [1]. Many NPC patients are already in the late stage at diagnosis [2]. Therefore, it is urgent to clarify the molecular pathogenesis underlying NPC.

EVI1 is a zinc finger transcription regulator encoded in human chromosome 3q26 that undergoes frequent rearrangements that can activate EVI1 expression [3]. Overexpression of EVI1 plays a critical role in many aggressive forms of cancer, including myeloid leukemia, colon cancer, breast cancer, pancreatic cancer and ovarian cancer [4-6]. However, the biological role and underlying mechanism of EVI1 in NPC are seldom reported.

The epithelial-mesenchymal transition (EMT) was originally described in the context of normal cell differentiation during early development; recently, it was well documented that EMT contributes to cancer metastasis [7]. Loss of E-cadherin is required for EMT to occur [8]. Several transcription factors (snail, Zeb, and Twist), which contribute to epigenetic silencing at the E-cadherin promoter in the form of hypermethylation or histone deacetylation, are known as E-cadherin repressors $[9,10]$.

Interestingly, studies have well demonstrated that EMT plays a significant role not only in tumor metastasis but also in tumor recurrence, which is highly linked to the biology of cancer stem cells (CSCs) [11, 12]. A series of proteins (e.g., CD44, CD133, and ALDH1) are widely used as CSC markers [13]. Our previous studies have identified ALDH1 and PKH26 as functional markers for identifying CSCs in NPC $[14,15]$. It is believed that CSCs contribute to tumor recurrence, relapse and resistance to chemo -/radiotreatment [16-18]. Chemotherapy combined with radiotherapy is the standard treatment for NPC [19]. Our previous studies have demonstrated that targeting CSCs in NPC overcomes radioresistance [15].

In the current study, we explored the biological role of EVI1 in NPC. We found that the EVI1 expression level was elevated in NPC tissues and cell lines. EVI1 interacted with snail and HDAC1 to corepress E-cadherin expression and thereby induce EMT. In addition, EVI1 promoted CSC properties by elevating CSC markers (SOX2 and c-myc). EVI1 activated the Wnt/ $\beta$-catenin pathway, which is involved in promoting CSC properties. Our study suggests that EVI1 is a therapeutic target for NPC.

\section{Materials and methods}

\section{Cell culture and samples collection}

NPC cell lines were maintained in our lab. These cells were cultured in RPMI 1640 medium (Invitrogen) with
$10 \%$ FBS. The immortalized nasopharyngeal epithelial cell line NP-69 cells were cultured in were cultured in keratinocyte serum-free medium (KSFM), supplemented with human recombinant epidermal growth factor (rEGF) and bovine pituitary extract. 293 T cells were cultured in Dulbecco's modified Eagle's medium, supplemented with $10 \%$ fetal bovine serum.

NPC samples were collected from Cancer Center of Guangzhou Medical University and Gaozhou People's Hospital. This study was conducted with the approval of the Ethics Committees of these hospitals.

\section{RT-PCR assay}

The total RNA was extracted from NPC cells and tissues by using Trizol, followed by transcribed into cDNA. The primers were listed in Table 1.

\section{Western blot assay, immunofluorescence assay and immunohistochemistry}

To perform western blot assay, total proteins were extracted from NPC cells and were subsequently resolved, transferred to polyvinylidene fluoride (PVDF) membranes. After blocked in 5\% non-fat milk/TBST, the membranes were incubated with primary antibodies and second antibodies, respectively. Then the images were captured with ChemiDocTM CRS+ Molecular Imager.

The immunofluorescence assay was carried out as our previous study described [20].

The immunohistochemistry assay was performed as previously described [21].

\section{Oligonucleotide transfection and lentivirus infection}

siRNAs for EVI1 and $\beta$-catenin were synthesized by GeneChem(Shanghai, China). The si-RNAs sequences were previously described [22, 23]. PcDNA.3.1- $\beta$-catenin and PcDNA.3.1-EVI1 were purchased from Santa Cruz. Oligonucleotide transfection was performed with Lipofectamine 2000 reagent (Invitrogen).

Lentiviral particles carrying EVI1(LV-EVI1), short hairpin RNA targeting EVI1 (sh-EVI1) and their control(LV-ctrl and sh-ctrl) were designed and synthesized GeneChem(Shanghai, China). Cells were infected with viral particles in the presence of $8 \mu \mathrm{g} / \mathrm{ml}$ polybrene.

\section{MTT and colony formation assay}

Cell viability was determined by the MTT assay. Briefly, 1000 cells/well were seeded in 96-well plates and allowed to attach overnight. Medium was removed and cells were washed with PBS. MTT was added to each well and the cells were incubated at $37^{\circ} \mathrm{C}$ for $2 \mathrm{~h}$. The reaction was stopped by lysing the cells with dimethyl sulfoxide (DMSO). The optical density was obtained at a wavelength of $570 \mathrm{~nm}$ using spectrophotometric analysis and the percentage cell viability was calculated. 
Table 1 Primers used in the study

\begin{tabular}{lll}
\hline & Forward & Reverse \\
\hline E-cadherin & CGAGAGCTACACGTTCACGG & GGGTGTCGAGGGAAAAATAGG \\
E-cadherin (promoter) & ACTCCAGGCTAGAGGGTCAC & CCGCAAGCTCACAGGTGCTTTGCAGTTCC \\
EVI1 & TTGAGGCCGTTAGATACCA & GCTTTCCTTGGAGCAATGTAGTT \\
GAPDH & GATCATCAGCAATGCCTCC & TCCACGATACCAAAGTTGTC \\
HDAC1 & TAACTATCAAAGGACACGCC & TACGAATGGTGTAACCACC \\
\hline
\end{tabular}

Cell survival rate was determined by the colony assay. Briefly, 200 cells/well were seeded in 6-well plates and allowed to grow for two weeks. Colonies were fixed with paraformaldehyde, stained with giemsa and counted using a microscope.

\section{Matrigel invasion assay}

The matrigel invasion assay was performed as previously described [24].

\section{Side population, tumor sphere formation assays}

The side population and tumor sphere formation assays were carried out as our previous study described [20].

\section{ALDH1 and PKH26 sorting}

The ALDH1 and PKH26 analysis were previously described, respectively $[14,15]$.

\section{Luciferase reporter assays}

For E-cadherin promoter assay, cells in 24-well plate were co-transfected with E-cadherin promoter or/and pcDNA.3.1-EVI1. $36 \mathrm{~h}$ after transfection, dual luciferase reporter assay was carried out by using a Dual-Luciferase Assay Kit (Promega).

The TOP/FOP Flash reporter assay was carried out according to our previous study [20].

\section{Chromatin immunoprecipitation}

We identified the EVI1- binding sites on $\beta$-catenin promoter region by using JASPAR (http://jaspar.genereg.net) and ALGGEN (http://alggen.lsi.upc.es) database.

We immunoprecipitated DNA-protein complexes from NPC cells by sing the Chromatin Immunoprecipitation Kit (Thermo Scientific, USA). IgG was used as a control. RT-PCR assay was used to determine the enrichment of $\beta$-catenin promoter region.

\section{Coimmunoprecipitation (co-IP)}

The cells were resuspended in RIPA lysis buffer, followed by immunoprecipitated with anti-EVI1, anti-HDAC1 or anti-Snail antibodies, respectively. After incubated overnight at $4{ }^{\circ} \mathrm{C}$, the proteins were further incubated with protein $\mathrm{G}$ agarose beads. Finally, the immunocomplexes were subjected to coomassie brilliant blue staining, mass spectrometry and western blot analysis. Anti-IgG was used as a negative control.

\section{Human serum albumin loaded arsenic trioxide preparation}

The human serum albumin loaded arsenic trioxide was prepared as previously described $[25,26]$.

\section{Cytotoxicity assay}

MTT assay was performed to determine 5-Fu, ALNP and radiation sensitivity. For 5 -Fu and ALNP toxicity assay, cells $\left(5 \times 10^{3} /\right.$ well $)$ were seeded in 96 -well plates and treated with different concentrations of 5 -Fu or ALNP. For radiation sensitivity assay, cells $\left(5 \times 10^{3} /\right.$ well $)$ were seeded in 96-well plates and treated with different Dose of radiation. Calculated rates were used for curve fitting and half maximal inhibitory concentration (IC50) calculations.

\section{Xenograft experiments}

Animal studies were conducted with the principles and procedures approved by the Committee on the Ethics of Animal Experiments of Guangzhou Medical University. To analyze EVI1's effect on cell growth, sh-ctrl or sh-EVI1 cells were mixed with growth factor-reduced phenol red-free Matrigel and were subcutaneously injected into both flanks of nude mice. Four weeks after implantation, xenografts were removed from the mice and weighed. Tumor volume was calculated using the following formula: $4 \pi / 3 \times($ width $/ 2) 2 \times($ length $/ 2)$.

Invasion assays were performed as previously described [27].

To analyze the effect of ionizing radiation and si-EVI1 as combination therapy, NPC cells were subcutaneously injected into athymic nude mice. When the tumors reached a size of $70 \mathrm{~mm}^{3}$, mice were randomly distributed to 4 groups(ctrl, ALNPs, radiation, ALNPs+radiation). PBS and ALNPs ( $2 \mathrm{mg} / \mathrm{kg} / \mathrm{per}$ mouse) were intraperitoneally injected into the mice every four days for eight times. Mice received 12 Gy dosage of radiation at day 7 and 14, respectively, with an X-ray generator.

To analyze the effect of 5-Fu and si-EVI1 as combination therapy, NPC cells were subcutaneously injected into athymic nude mice. When the tumors reached a size of $70 \mathrm{~mm}^{3}$, mice were randomly distributed to 4 
groups(ctrl, ALNPs, 5-Fu, ALNPs+ 5-Fu). PBS, ALNPs ( $2 \mathrm{mg} / \mathrm{kg} /$ per mouse) and 5 -Fu ( $20 \mathrm{mg} / \mathrm{kg} /$ per mouse) were intraperitoneally injected into the mice every four days for eight times.

\section{Statistical analysis}

Numerical data are expressed as the mean \pm standard deviation (SD). The difference between means was analyzed using Student's t-test and differences with $p<0.05$ were considered statistically significant.

\section{Results}

EVI1 expression was elevated in NPC tissues and cell lines We first examined the expression level of EVI1 in NPC tissues and adjacent nonneoplastic nasopharyngeal tissues. EVI1 expression was found to be higher in NPC tissues than in adjacent nonneoplastic nasopharyngeal tissues (Fig. 1a). In parallel, the expression levels of EVI1 were increased in NPC cell lines (5-8F, CNE1, CNE2 and 6-10B) compared with that in the NP-69 cell line. Among the NPC cell lines, 5-8F cells had the highest expression of EVI1, while 6-10B had the lowest expression of EVI1 (Fig. 1b). An immunohistochemistry (IHC) staining assay revealed that high expression of EVI1 was frequent in primary NPC tissues (89/118, 75.4\%) compared with that in nonneoplastic nasopharyngeal tissues (6/50, 12\%) (Fig. 1c). In addition, we examined the amplification of EVI1 by fluorescence in situ hybridization in primary NPC tissues (Fig. 1d).

\section{EVI1 influenced the cell proliferation and invasive} capacity of NPC cells in vitro and in vivo To further clarify the EVI1-mediated molecular events in NPC cells, we conducted a genome-wide analysis to globally characterize EVI1-regulated transcriptome changes. We compared the transcript expression profiles between sh-ctrl and sh-EVI1 cells by using an RNA sequence assay (Additional file 1: Figure S1A and B). A Gene Ontology (GO) assay indicated that the differentially expressed mRNAs were enriched in cell proliferation, cell metastasis, and CSC properties and in drug-resistant signaling pathways (Additional file 1: Figure $\mathrm{S} 1 \mathrm{C}$ ). In addition, a Gene Set Enrichment Analysis (GSEA) assay showed that EVI1 might play a role in

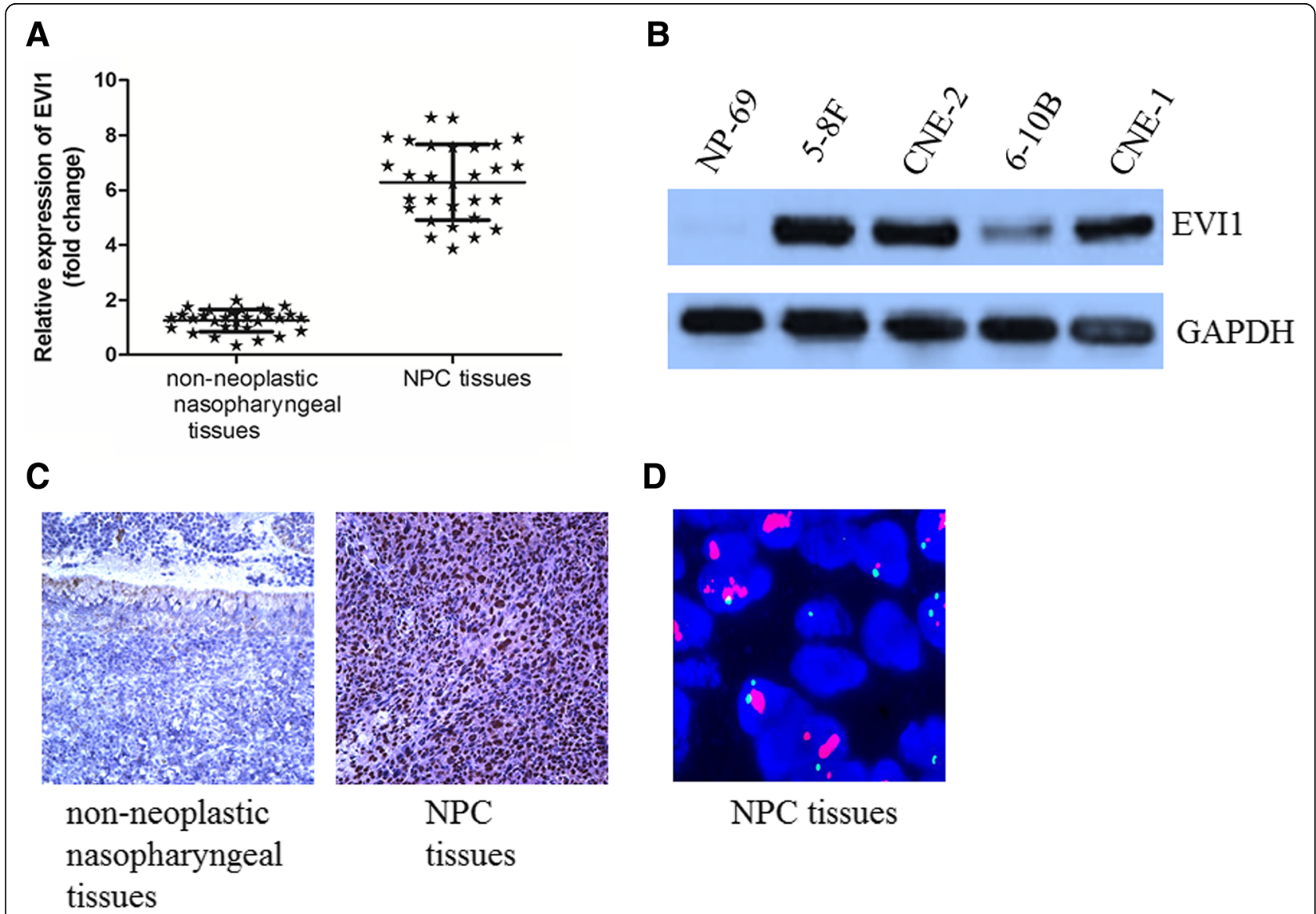

Fig. 1 EVI1 expression was elevated in NPC tissues and cell lines (a) EVI1 expression was elevated in NPC tissues compared with that in adjacent nonneoplastic nasopharyngeal tissues. (b) The expression levels of EVI1 were increased in NPC cell lines. (c) EVI1 expression was frequently elevated in NPC tissues. (d) EVI1 was amplified in primary NPC tissues 
AKT and ERK signaling pathway (Additional file 1: Figure S1D).

Based on the above findings, we asked whether EVI1 promoted the cell proliferation and invasive capacity of NPC. We knocked down EVI1 in the 5-8F and CNE-2 cell lines (which had the highest level of endogenous EVI1) and overexpressed EVI1 in the 6-10B cell line (which had the lowest level of endogenous EVI1) (Fig. 2a). Downregulation of EVI1 significantly decreased cell proliferation, whereas overexpression of EVI1 increased cell proliferation as revealed by an MTT assay (Fig. 2b). In addition, EVI1 downregulation decreased the ability of NPC to form cell colonies, whereas overexpression of EVI1 increased cell colony formation (Fig. 2c, Additional file 2: Figure S2A). Downregulation of EVI1 inhibited the invasive ability of 5-8F and CNE-2 cells, while overexpression of EVI1 markedly increased the invasive capacity of $6-10 \mathrm{~B}$ cells, as determined by Matrigel invasion assays (Fig. 2d).

Subsequently, we performed an in vivo study to analyze the role of EVI1 in cell growth and invasion. A tumorigenesis study was performed to confirm the growth inhibitory effect of EVI1 downregulation in vivo. 5-8F cells treated with sh-ctrl or sh-EVI1 cells were inoculated into the back of nude mice. Compared with sh-ctrl cell-derived xenograft tumors, sh-EVI1 cell-derived xenograft tumors grew more slowly (Fig. $2 \mathrm{e})$. The mean weight of sh-EVI1 cell-derived xenograft tumors was also significantly lower than that of sh-ctrl cell-derived xenograft tumors (Fig. 2f). Next, the tumor sections were stained for $\mathrm{Ki}-67$ expression to quantitatively assess the proliferation index in xenograft tumors (Fig. 2g). These results suggested that EVI1 downregulation exerted an inhibitory effect on the tumorigenesis of NPC cells in vivo. An experimental metastatic assay was then performed to investigate the in vivo effect of EVI1 knockdown on NPC metastasis. 5-8F cells treated with sh-ctrl or sh-EVI1 were injected into the lateral tail vein of severe combined immunodeficient (SCID) mice. The sh-EVI1 cells formed fewer and smaller nodes per lung than the sh-ctrl cells (Fig. 2h).

Taken together, these data suggest that EVI1 is involved in the control of NPC proliferation and metastasis both in vitro and in vivo.

\section{EVI1 regulated E-cadherin expression via snail in NPC cells}

Since the EMT phenotype contributes to cancer metastasis, we asked whether EVI1 regulates the EMT phenotype. 5-8F and CNE-2 cells were two NPC cell lines which have undergone EMT phenotype. The morphology change of the two cell lines was indicated in Additional file 2: Figure S2A. Indeed, knockdown of EVI1 elevated E-cadherin expression but decreased $\mathrm{N}$-cadherin and vimentin. Overexpression of EVI1 had the opposite effects (Fig. 3a).

Loss of E-cadherin is considered a fundamental event in EMT. Loss of E-cadherin promotes cancer metastasis via multiple downstream transcriptional pathways [8]. We thus asked how EVI1 regulates E-cadherin. EVI1 regulated E-cadherin expression not only at the protein level (Fig. 3a) but also at the mRNA level (Fig. 3b,

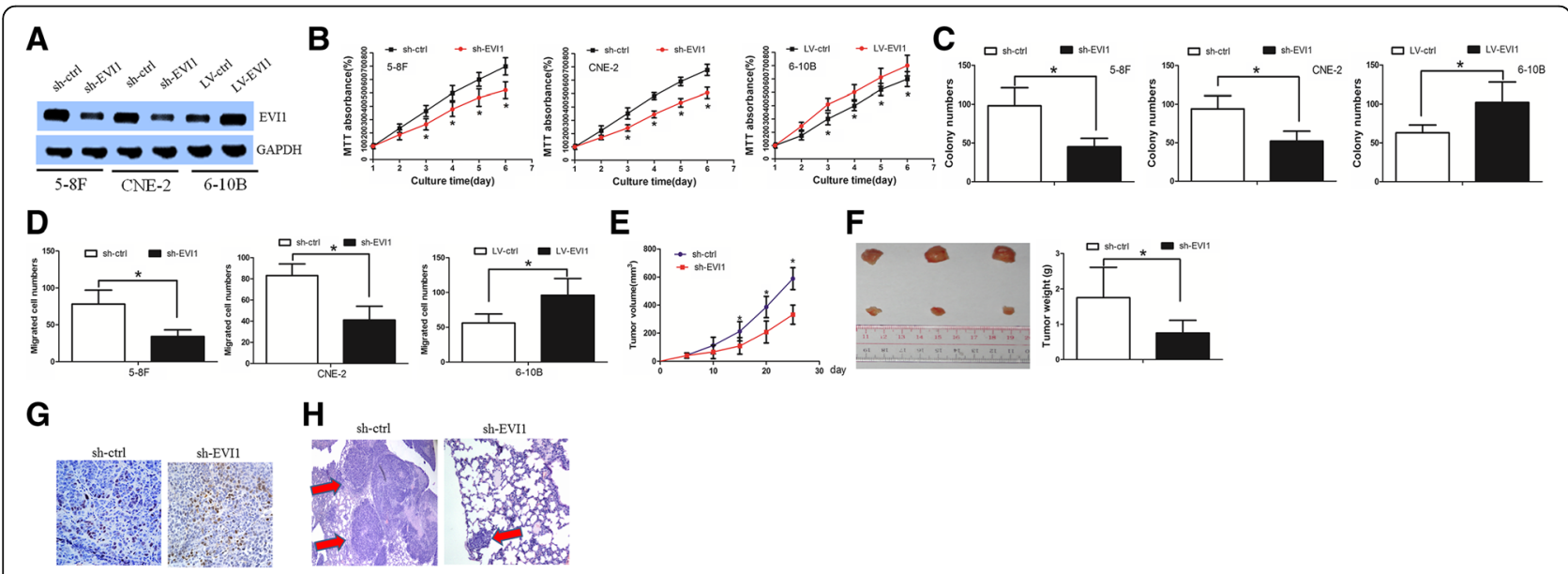

Fig. 2 EVI1 influenced the cell proliferation and invasive capacity of NPC cells. (a) The EVI1 downregulation and overexpression efficiency was examined by a western blot assay. (b) Downregulation of EVI1 significantly decreased the cell proliferation ability, whereas overexpression of EVI1 increased the cell proliferation ability. (c) EVI1 downregulation decreased the NPC cell colony formation ability, whereas overexpression of EVI1 increased the cell colony formation ability. (d) Downregulation of EVI1 inhibited the invasive ability of 5-8F and CNE-2 cells, while overexpression of EVI1 markedly increased the invasive capacity of 6-10B cells. (e) Compared with sh-ctrl cell-derived xenograft tumors, sh-EVI1 cell-derived xenograft tumors grew more slowly. (f) The mean weight of sh-EVI1 cell-derived xenograft tumors was also significantly lower than that of sh-ctrl cell-derived xenograft tumors. (g) A Ki-67 staining assay revealed that EVI1 downregulation decreased the cell-derived xenograft proliferation rate. (h) sh-EVI1 cells formed fewer and smaller nodes per lung than sh-ctrl cells 


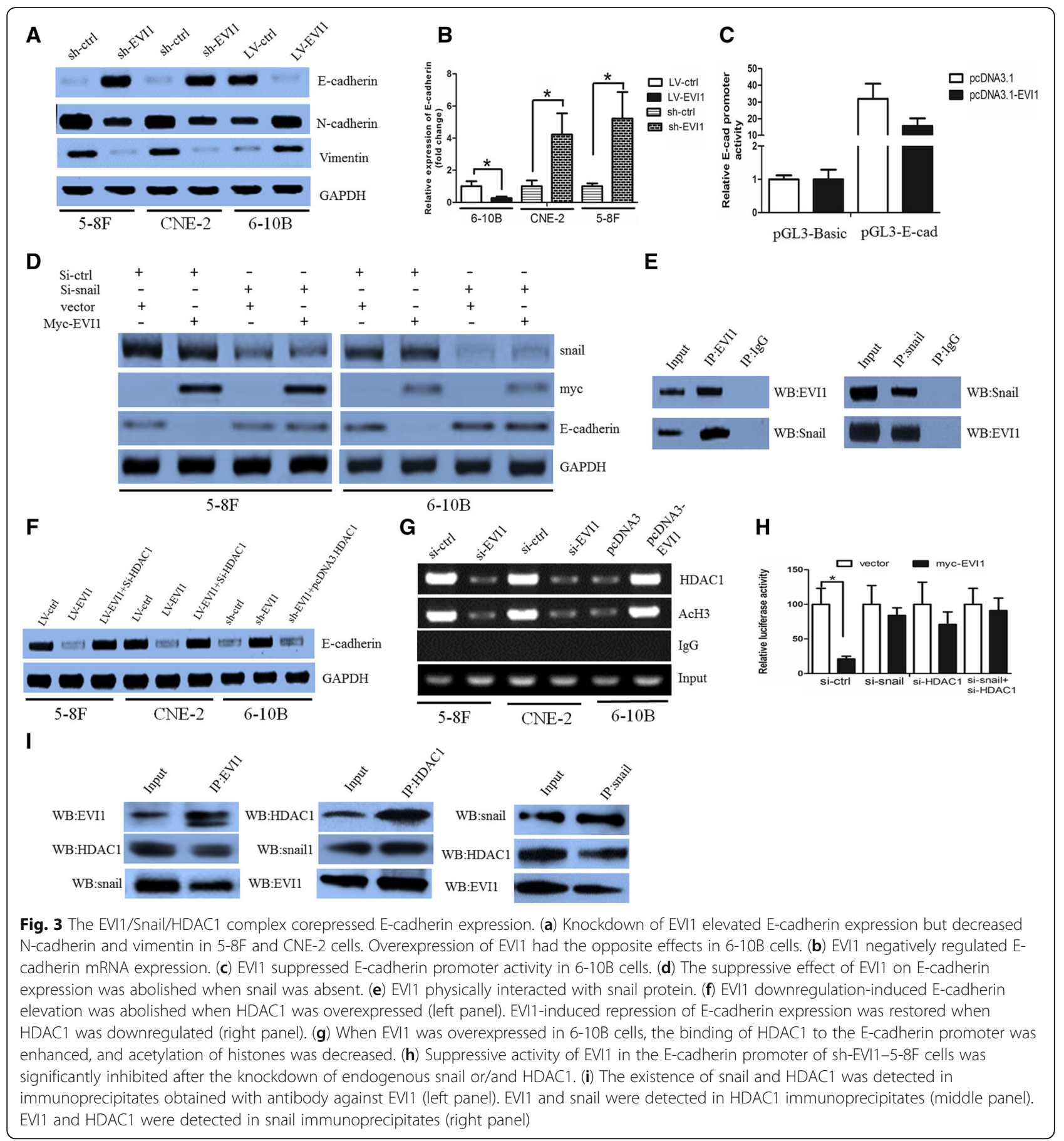

Additional file 2: Figure S2B). These data suggested that EVI1 regulation of E-cadherin occurred at the transcriptional level. We further designed a luciferase reporter construct (contains the $5^{\prime}$-flanking region of the E-cadherin gene) to determine whether EVI1 could downregulate E-cadherin promoter activity. EVI1 suppressed E-cadherin promoter activity when 6-10B cells were cotransfected with pcDNA3.1-EVI1 and pGL3-E-cadherin promoters (Fig. 3c).
To explore the precise molecular mechanisms and relevant interactions with EVI1, mass spectrometry was used in $5-8 \mathrm{~F}$ cells, and this analysis yielded a list of potential EVI1-interacting proteins (Additional file 2: Figure $\mathrm{S} 2 \mathrm{C}$ ). Snail was one of the predicted proteins that interacted with EVI1.

A previous study demonstrated that snail is a master transcriptional repressor of E-cadherin [28, 29]. We hypothesized that EVI1 may recruit snail to silence 
E-cadherin. To confirm our hypothesis, the basic levels of endogenous snail were knocked down by specific small interfering RNA (siRNA) in EVI1-low-expressed 6-10B cells and sh-EVI1-5-8F cells. Then, myc-EVI1 was transfected into these cells to examine whether EVI1 could still repress E-cadherin expression in the absence of snail. Interestingly, the suppressive activity of EVI1 on E-cadherin expression was abolished when snail was absent as determined by the western blot assay (Fig. 3d).

To identify the direct interaction between EVI1 and snail, a coimmunoprecipitation assay was performed in LV-EVI1-6-10B cells. It was revealed that EVI1 physically interacts with snail protein (Fig. 3e). The confocal immunofluorescence assay was performed to confirm the subcellular localization of EVI1 and snail in LV-EVI1-6-10B cells. The nuclear colocalization of EVI1 and snail proteins was clearly detected (Additional file 2: Figure S2D).

Taken together, these data indicated that snail was indispensable for the suppressive effect of EVI1 on E-cadherin.

\section{The EVI1/snail/HDAC1 complex corepressed the E- cadherin expression}

EVI1 has been suggested to associate with HDAC1, a histone deacetylase that plays an important role in the transcriptional repression of E-cadherin [30]. In addition, our data revealed that HDAC1 interacted with EVI1 in NPC cells (Additional file 2: Figure S2C). We reasoned that the EVI1-HDAC1 interaction may also contribute to the repression of E-cadherin.

In sh-EVI1-5-8F cells, EVI1 downregulation-induced E-cadherin elevation was abolished when HDAC1 was overexpressed (Fig. 3f, left panel). In LV-EVI1-6-10B cells, the EVI1-induced repression of E-cadherin expression was restored when HDAC1 was downregulated by siRNA (Fig. 3f, right panel). When EVI1 was knocked down in $5-8 \mathrm{~F}$ cells, the binding of HDAC1 to the E-cadherin promoter was abolished, and the acetylation of histones was increased (Fig. 3g, left panel). When EVI1 was overexpressed in 6-10B cells, the binding of HDAC1 to the E-cadherin promoter was enhanced, and the acetylation of histones was decreased (Fig. 3g, right panel). Taken together, these data indicated that EVI1 may repress E-cadherin expression via the recruitment of HDAC1 to the E-cadherin promoter.

Subsequently, a luciferase reporter assay was used to examine whether the suppressive effect of EVI1 on the E-cadherin promoter requires both snail and HDAC1. Sh-EVI1-5-8F cells were transfected with specific siRNAs targeted to snail and HDAC1. Subsequently, these cells were reintroduced with the myc-EVI1 plasmid, and the luciferase activity of the E-cadherin promoter was measured. The suppressive activity of EVI1 in the
E-cadherin promoter of sh-EVI1-5-8F cells was significantly inhibited after the knockdown of endogenous snail but was only partially inhibited after the downregulation of HDAC1 (Fig. 3h). Compared with treatment with each siRNA alone, a combined treatment with si-HDAC1 and si-snail caused the repressive activity to be substantially enhanced (Fig. 3h).

We performed a coimmunoprecipitation assay to examine whether EVI1, snail and HDAC1 could interact with each other in 5-8F cells. As shown in Fig. 3i (left panel), the presence of snail and HDAC1 was detected in immunoprecipitates obtained with antibody against EVI1. In parallel, EVI1 and snail were detected in HDAC1 immunoprecipitates (Fig. 3i, middle panel). EVI1 and HDAC1 were detected in snail immunoprecipitates (Fig. 3i, right panel).

Consequently, we hypothesized that EVI1, snail, and HDAC1 formed a corepressor complex to repress E-cadherin expression.

\section{EVI1 regulated CSC properties in NPC}

Our previous study revealed that PKH26+ and ALDH1+ NPC cells had CSC properties [14, 15]. We found that PKH26 + -labeled and ALDH1 + -labeled cells were significantly decreased among sh-EVI1-5-8F and sh-EVI1-CNE-2 cells compared with those among sh-ctrl cells (Fig. 4a). However, when EVI1 was overexpressed in 6-10B cells, PKH26 +- and ALDH1 +-labeled cells were significantly increased (Fig. 4a). In parallel, the sphere formation ability was impaired in sh-EVI1-5-8F and sh-EVI1-CNE-2 cells (Fig. 4b) but was enhanced in LV-EVI1-6-10B cells (Fig. 4b). The pluripotent transcription factors (SOX2, Nanog, c-Myc, and Oct4) were implicated in the self-renewal of CSCs, including in NPC CSCs [31]. Our data revealed that the expression levels of SOX2, Nanog and c-myc were decreased in sh-EVI1-5-8F and sh-EVI1-CNE-2 cells (Fig. 4c) but were enhanced in LV-EVI1-6-10B cells (Fig. 4c). These data suggested that EVI1 regulated CSC properties in NPC.

\section{EVI1 regulated the Wnt/ $\beta$-catenin signaling pathway in NPC}

Our previous study demonstrated that the Wnt/ $\beta$-catenin signaling pathway regulated CSC properties, including those in NPC [32-34]. We thus asked whether EVI1 exerted its function in CSCs via the $\mathrm{Wnt} / \beta$-catenin signaling pathway. EVI1 downregulation inhibited $\beta$-catenin expression in the total cell lysate and in the nuclear fraction. In contrast, forced expression of EVI1 enhanced $\beta$-catenin expression in the total cell lysate and in the nuclear fraction (Fig. 5a). Consistent with these results, the $\mathrm{Wnt} / \beta$-catenin activity was repressed when EVI1 was knocked down as revealed by a TOP/ 


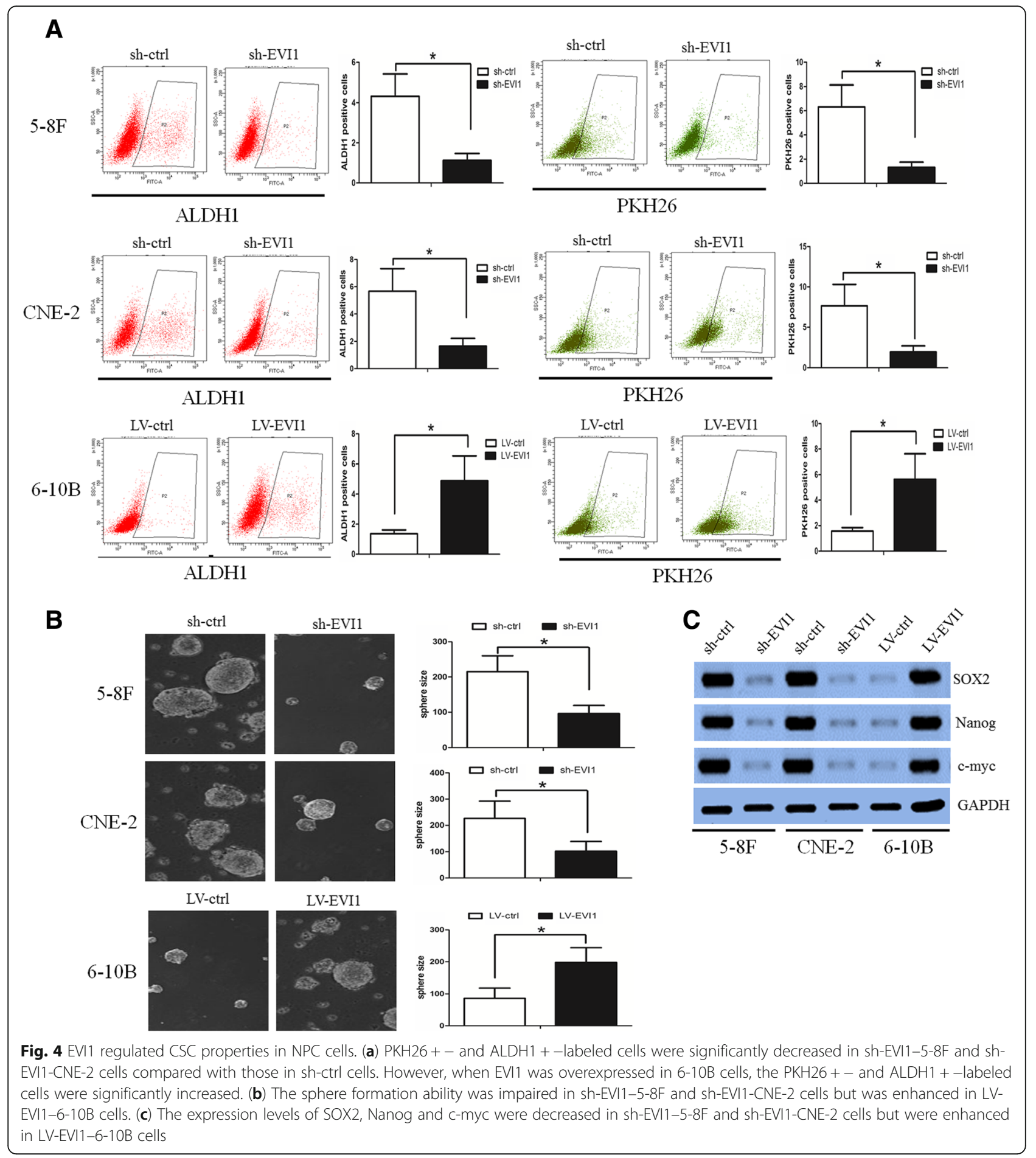

FOP Flash reporter assay (Fig. 5b). In addition, EVI1 overexpression elevated the $\mathrm{Wnt} / \beta$-catenin activity (Fig. $5 b)$, and the expression levels of the $\beta$-catenin downstream targets AXIN2 and c-myc were downregulated in sh-EVI1 cells and upregulated in LV-EVI cells (Fig. 5c). We then performed rescue experiments through the stable expression of constitutively active $\beta$-catenin in
sh-EVI1 cells and knocked down $\beta$-catenin in LV-EVI1 cells to confirm that the stemness properties induced by EVI1 were mediated through the $\mathrm{Wnt} / \beta$-catenin signaling pathway. The enforced expression and si- $\beta$-catenin were confirmed by a western blot assay (Additional file 2: Figure S2E), and the functional effects on CSCs upon silencing or overexpression of EVI1 were partially 


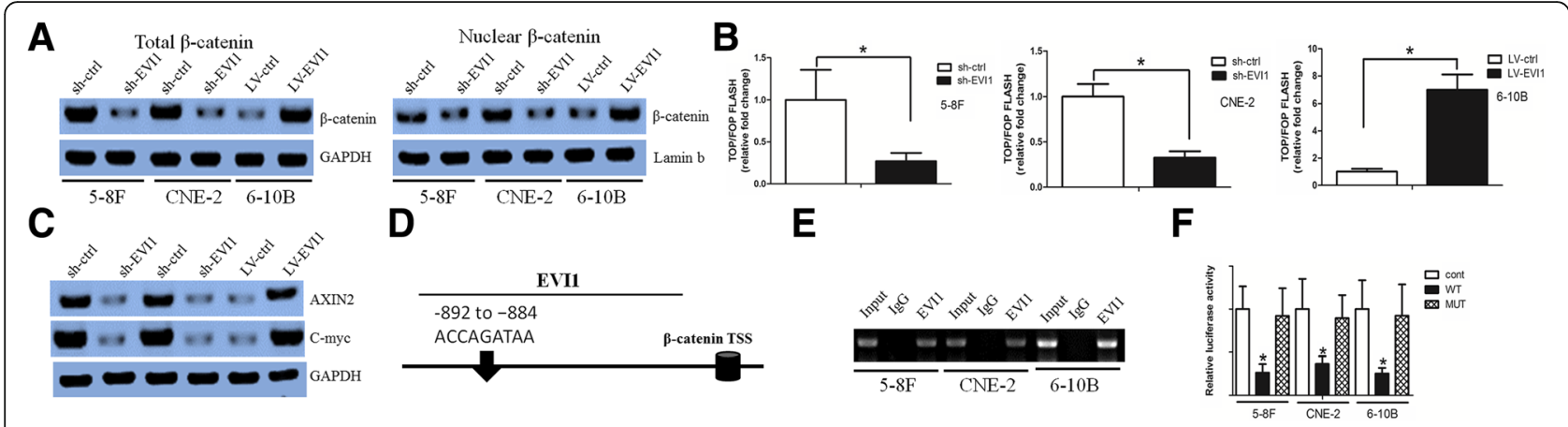

Fig. 5 EVI1 regulated the Wnt/ $\beta$-catenin signaling pathway in NPC. (a) EVI1 downregulation inhibited $\beta$-catenin expression in the total cell lysate and the nuclear fraction. In contrast, forced expression of EVI1 enhanced $\beta$-catenin expression in the total cell lysate and the nuclear fraction. (b) The Wnt/ $\beta$-catenin activity was repressed when EVI1 was knocked down as revealed by a TOP/FOP Flash reporter assay (left panel). EVI1 elevated Wnt/ $\beta$-catenin activity when EVI1 was overexpressed (right panel). (c) The expression levels of $\beta$-catenin downstream targets AXIN2 and c-myc were downregulated in sh-EVI1 cells and were upregulated in LV-EVI1 cells. (d) The $\beta$-catenin promoter region contains one putative EVI1-binding site. (e) A ChIP assay demonstrated that EVI1 bound to the $\beta$-catenin promoter. (f) EVI1 positively regulated the $\beta$-catenin promoter activity

rescued by the forced expression of $\beta$-catenin or si- $\beta$-catenin, respectively ((Additional file 2: Figure S2F-J).

\section{EVI1 regulated $\beta$-catenin expression by binding to its promoter}

We used LASAGNA-Search 2.0 to determine that the $\beta$-catenin promoter region contained one putative EVI1-binding site (Fig. 5d). A chromatin immunoprecipitation (ChIP) assay was used to determine whether EVI1 binds to the $\beta$-catenin promoter in $5-8 \mathrm{~F}$ and $6-10 \mathrm{~B}$ cells. In addition, we found significant enrichment of this specific region from immunoprecipitated chromatin DNA when compared to negative control (IgG) pulldown (Fig. 5e). Subsequently, wild-type and mutant $\beta$-catenin promoters were cloned into the pGL3-Basic vector to examine the effect of EVI1 on promoter activity. The wild-type and mutant promoters were cotransfected with EVI1 plasmid into 5-8F and 6-10B cells. We observed that the luciferase activities of the wild-type promoter, instead of the mutant promoter, significantly increased when EVI1 was cotransfected (Fig. 5f). These data indicated that EVI1 increased the transcriptional activity of the $\beta$-catenin promoter.

To further clarify whether EVI1 exerts oncogenic activities via WNT signaling pathway, we tested the efficacy of WNT inhibitor drug Cardamonin (CAS 19309-14-9) in nasopharyngeal carcinoma cell lines (5-8F, CNE-2 and LV-EVI1-6-10B). We revealed that CAS 19309-14-9 inhibited growth and invasion in these cell lines (Additional file 3: Figure S4A-C). Interestingly, Wnt agonist drug CAS 853220-52-7 reinforced tumorigenicity in EVI1 knockdown cells (sh-EVI1-5-8F and sh-EVI1-CNE2) (Additional file 3: Figure S4D).
EVI1 upregulation predicted an unfavorable prognosis and contributed to chemo-/radioresistance in NPC cells Next, we explored the association between EVI1 expression and NPC patient prognosis. We present the associations between EVI1 expression and patient clinicopathological features in Table 2. Parameters such as gender $(P=0.121)$, age $(P=0.122)$ and EBV infection $(P=0.108)$ were not significantly associated with EVI1 expression. However, high EVI1 expression was significantly correlated with tumor size $(P=0.011)$, lymph node metastasis $(P=0.002)$, distant metastasis $(P=$ $0.000)$ and late clinical stage $(P=0.011)$. In the Kaplan-Meier analysis assay, we found that high-level EVI1 expression was correlated with shorter overall survival (OS) and progression-free survival (PFS) (Fig. 6a and $\mathrm{b}, P<0.05)$.

We then examined the effect of EVI1 on chemo-/radioresistance. Sh-ctrl, sh-EVI1, LV-ctrl and LV-EVI1 cells were treated with different doses of 5 -Fu, and cell viability was examined by an MTT assay. We found that knockdown of EVI1 increased NPC cell sensitivity, while overexpression of EVI1 decreased NPC cell sensitivity to 5-Fu (Fig. 6c). Subsequently, sh-ctrl, sh-EVI1, LV-ctrl and LV-EVI1 cells were treated with different doses of radiation. Similarly, EVI1 downregulation increased the NPC cell radiosensitivity, while overexpression of EVI1 decreased the NPC cell sensitivity to irradiation as revealed by the MTT assay (Fig. 6d). These data indicated that EVI1 conferred chemo-/radioresistance in NPC cells.

\section{Correlation of EVI1 with EMT and CSC-related genes}

We then analyzed the correlation of EVI1 with EMT and CSC-related genes. In EMT-related genes, EVI1 expression was negatively associated with E-cadherin expression (Fig. 6e, Additional file 4: Figure S3K) but positively associated with $\mathrm{N}$-cadherin and vimentin expression 
Table 2 Correlation of EVI1 expression in tissue with patients clinicopathological variables in NPC

\begin{tabular}{|c|c|c|c|c|}
\hline \multirow[b]{2}{*}{ Variables } & \multicolumn{4}{|l|}{ EVl1 } \\
\hline & All case $(n=98)$ & Low expression $(n=35)$ & High expression $(n=63)$ & $P$ Value* \\
\hline \multicolumn{5}{|l|}{ Age(years) } \\
\hline$<60$ & 38 & 10 & 28 & \multirow[t]{2}{*}{0.122} \\
\hline$\geqq 60$ & 60 & 25 & 35 & \\
\hline \multicolumn{5}{|l|}{ Sex } \\
\hline Male & 69 & 28 & 41 & \multirow[t]{2}{*}{0.121} \\
\hline Female & 29 & 7 & 22 & \\
\hline \multicolumn{5}{|l|}{ Smoking } \\
\hline Yes & 59 & 24 & 35 & \multirow[t]{2}{*}{0.207} \\
\hline No & 39 & 11 & 28 & \\
\hline \multicolumn{5}{|l|}{ EBV } \\
\hline Positive & 66 & 20 & 46 & \multirow[t]{2}{*}{0.108} \\
\hline Negative & 32 & 15 & 17 & \\
\hline \multicolumn{5}{|c|}{ T classification } \\
\hline $\mathrm{T} 1-\mathrm{T} 2$ & 42 & 9 & 33 & \multirow[t]{2}{*}{$0.011^{*}$} \\
\hline T3-T4 & 56 & 26 & 30 & \\
\hline \multicolumn{5}{|c|}{ N classification } \\
\hline No-N1 & 58 & 28 & 30 & \multirow[t]{2}{*}{$0.002^{*}$} \\
\hline N2-N3 & 40 & 7 & 33 & \\
\hline \multicolumn{5}{|c|}{ M classification } \\
\hline MO & 46 & 27 & 19 & \multirow[t]{2}{*}{$0.000^{*}$} \\
\hline M1 & 52 & 8 & 44 & \\
\hline \multicolumn{5}{|c|}{ TNM clinical stage } \\
\hline I, II & 59 & 27 & 32 & \multirow[t]{2}{*}{$0.011^{*}$} \\
\hline III, IV & 39 & 8 & 31 & \\
\hline
\end{tabular}

The symbol * means statistically significant

(Fig. 6e, Additional file 2: Figure S2K). In CSC-related genes, EVI1 expression was positively associated with SOX2, c-myc and Nanog expression (Fig. 6f, Additional file 2: Figure S2K).

\section{Arsenic trioxide exerted an antitumor effect in NPC cells} Arsenic trioxide (ATO) has been reported to degrade the oncogenic EVI1 protein [35], and thus, we further asked whether ATO exerts an antitumor effect in NPC cells. We chose the 5-8F and CNE-2 cell lines (which had the highest expression levels of EVI1) for further study. We first used folate (FA)-labeled human serum albumin (HSA) to load ATO and form arsenite-loaded nanoparticles (ALNPs). Transmission electron microscopy (TEM) imaging revealed that the ALNPs were uniform in size distribution, with core-shell nanostructures (Additional file 4: Figure S3A). The size of the ALNPs was approximately $50-60 \mathrm{~nm}$ as determined by dynamic light scattering (DLS) (Additional file 4: Figure S3B). To validate the efficiency at the cellular level, we determined the cellular uptake of FITC-labeled ALNPs by fluorescence microscopy. We performed an MTT assay to evaluate the half-maximal inhibitory concentration of ALNPs and free ATO in NPC cells and found that the ALNP drug delivery system, compared with free ATO, significantly elevated the cytotoxicity to NPC cells (Additional file 4: Figure S3C). In addition, we found that ALNPs degraded the EVI1 protein in these cell lines (Additional file 4: Figure S3D).

ALNP treatment inhibited NPC colony formation and invasion ability in vitro (Fig. 7a-b). A western blot assay revealed that ALNPs increased E-cadherin expression and decreased $\mathrm{N}$-cadherin and vimentin expression (Fig. 7c). In addition, ALNPs eliminated CSC activity in NPC cells (Fig. 7d-g). The CSC-related markers were decreased in ALNP-treated NPC cells (Fig. 7h). Interestingly, ALNPs also increased NPC cell sensitivity to 5 - Fu and radiation (Fig. $7 \mathrm{i}-\mathrm{j}$ ). These data suggest that ALNPs mimicked the effect of EVI1 downregulation on NPC cells in vitro. We also tested whether ATO still had an effect on EVI1 knockdown cells. We found that ATO treatment had limited effect on EVI1 knockdown 


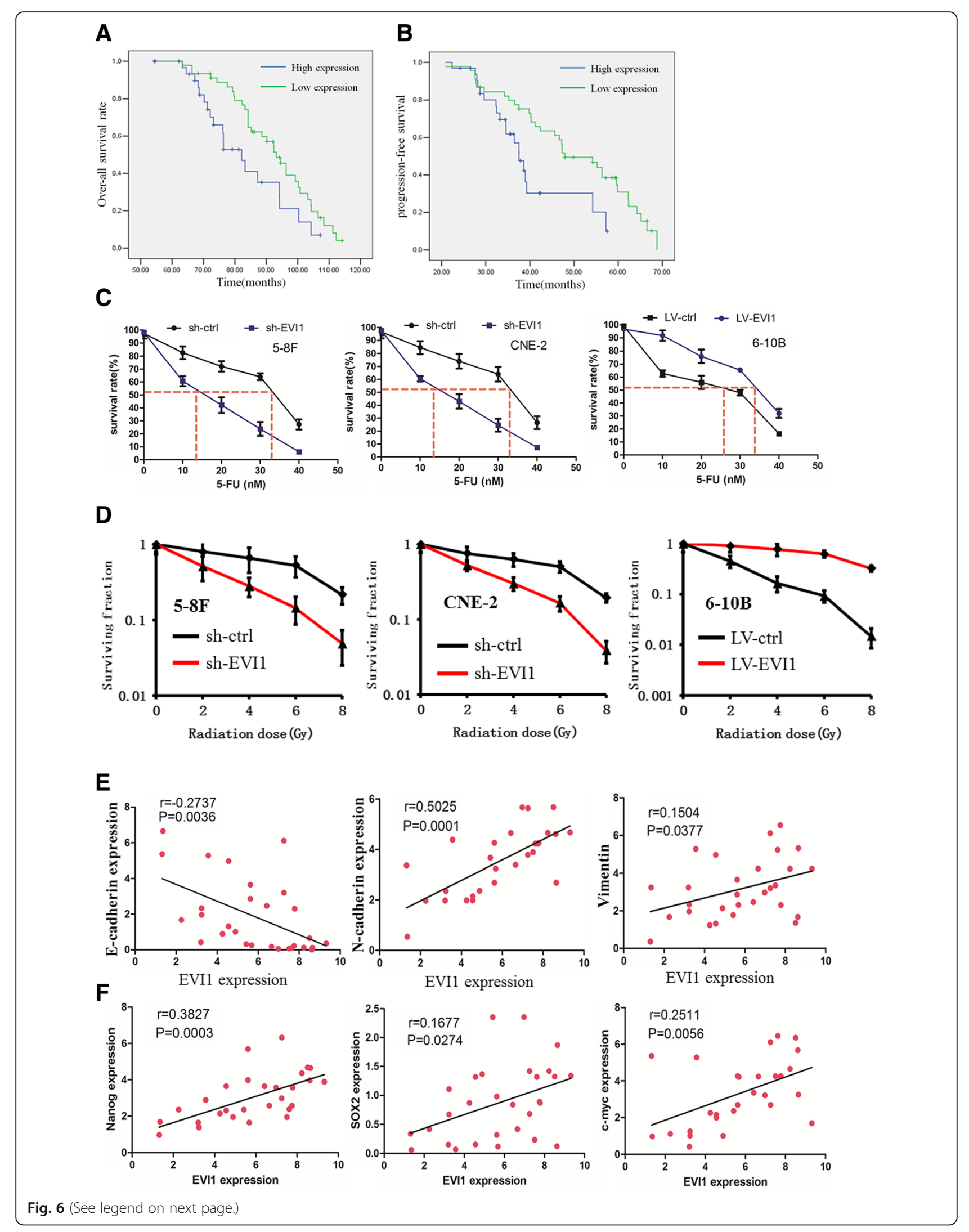


(See figure on previous page.)

Fig. 6 EVI1 upregulation predicted an unfavorable prognosis and contributed to chemo-/radioresistance in NPC cells. (a) High-level EVI1 expression was correlated with a shorter OS rate. (b) High-level EVI1 expression was correlated with a shorter PFS rate. (c) Knockdown of EVI1 increased NPC cell sensitivity to 5-Fu, while overexpression of EVI1 decreased NPC cell sensitivity to 5-Fu as revealed by an MTT assay. (d) EVI1 downregulation increased NPC cell radiosensitivity, while overexpression of EVI1 decreased the NPC cell sensitivity to irradiation as revealed by an MTT assay. (e) EVI1 expression was negatively associated with E-cadherin expression, but positively associated with $\mathrm{N}$-cadherin and Vimentin expression.(f) expression was positively associated with Nanog, SOX2 and c-myc expression

cells(sh-EVI1-5-8F and sh-EVI1-CNE-2 cells)(data not shown). However, in cell line LV-EVI1-6-10B, EVI-1 overexpression effect on cell growth and invasion could be partly counteracted by ATO treatment(Additional file 3: Figure S4E). These data suggest that ATO exert its function on NPC mainly on EVI1.

Finally, we analyzed the antitumor effect of ALNPs and found that these nanoparticles decreased the tumor growth in vivo. Interestingly, when combined with 5-Fu or radiation treatment, ALNPs had synergistic effects with both $5-\mathrm{Fu}$ and radiation (Fig. 7k-l, Additional file 4: Figure S3E-F). To evaluate the systemic animal toxicity of ALNPs, the main organ tissues of mice were subjected to $H \& E$ staining. We observed that all the organs maintained their typical structures and did not exhibit appreciable microscopic lesions (Additional file 4: Figure S3G). These data suggested that ALNPs may be an effective biosafety treatment.

\section{Discussion}

Previous studies have well documented the abnormal expression and biological role of EVI1 in a series of cancers [36, 37]. As an oncogene located on chromosome 3 q26 [38], EVI1 is amplified in NPC tissues [39]. A recent study suggested that EVI1 may be involved in NPC tumorigenesis [40]. However, the biological role and the underlying mechanism of EVI1 in NPC have seldom been reported.

The current study revealed that the EVI1 expression level was upregulated in NPC tissues and cell lines. The reasons for the high expression of EVI1 differ in various cancers. Genetic rearrangements of the EVI1 locus at chromosomal region 3q26 contribute to the elevated expression of EVI1 in myeloid leukemia [41]; however, high copy number gains were the main cause of abnormal EVI1 expression levels in ovarian cancer [42]. In addition, alternative mechanisms may also lead to the aberrant expression of EVI1 [41]. We found that DNA amplification contributed to the elevated expression of EVI1 in NPC as revealed by a fluorescence in situ hybridization assay. This result was consistent with previous findings [40].

Other reports have documented that EVI1 promotes cell proliferation, migration and metastasis [23, 43-45]. Consistent with these results, our data demonstrated that EVI1 contributed to NPC cell growth and invasion both in vitro and in vivo. These findings indicated that EVI1 may function as an oncogene in NPC. Loss of E-cadherin is regarded to enable metastasis by disrupting intercellular contacts-an early step in metastatic dissemination [8]. Previous research found that EVI1 negatively regulates E-cadherin $[36,46]$. However, the underlying mechanism is still poorly understood. In our study, we used a mass spectrometry assay to identify snail and HDAC1 as two important proteins associated with EVI1. Previous documents have demonstrated that snail and epigenetic modulator HDACs play significant roles in the metastasis of carcinomas. Oncogenes can interact with snail and HDACs, form a multiprotein complex and thereby inhibit E-cadherin expression. For instance, Nie et al. showed that the hepatitis $\mathrm{C}$ virus core protein recruits snail and $\mathrm{HDAC} 1 / \mathrm{HDAC} 2$ to the E-cadherin promoter and decreases E-cadherin expression [47]. Tong et al. reported that EZH2 inhibits E-cadherin expression by forming a corepressor complex with HDAC1/HDAC2 and snail [48]. Concordantly, we found that EVI1 recruited snail and HDAC1 to decrease E-cadherin expression. Notably, EVI1 may directly target PTEN and regulate PI3K/AKT activity [49]. Our GSEA model revealed that EVI1 may also regulate the PI3K/ AKT pathway. Thus, EVI1 might repress E-cadherin expression via the PTEN/ PI3K/AKT pathway. Subsequently, we showed that EVI1 elevated N-cadherin and vimentin expression in NPC cells. Overexpression of EVI1 caused a spindle shape and increased lamellipodia in NPC cells. We speculated that EVI1 induced an EMT phenotype and thus promoted NPC cell metastasis. Our findings conflicted with those of a previous study [36], which demonstrated that EVI1 is dispensable for EMT but is required for metastasis. This may be the reason that EVI1 exerted its function in different cell contexts.

Cancer cells that undergo EMT can generate CSCs [50]. A previous study revealed that EVI1 contributes to prostate cancer CSC formation and thus promotes prostate cancer initiation [45]. In chronic myeloid leukemia, Evi1-high leukemic cells possessed a greater potential than EVI1-low cells in oncogenic self-renewal, and EVI1 was a functional marker of stem cells [51]. However, how EVI1 regulates CSC properties is still poorly understood.

Our previous study revealed that PKH26+ and ALDH1 + NPC cells display CSC properties $[14,15]$. We 


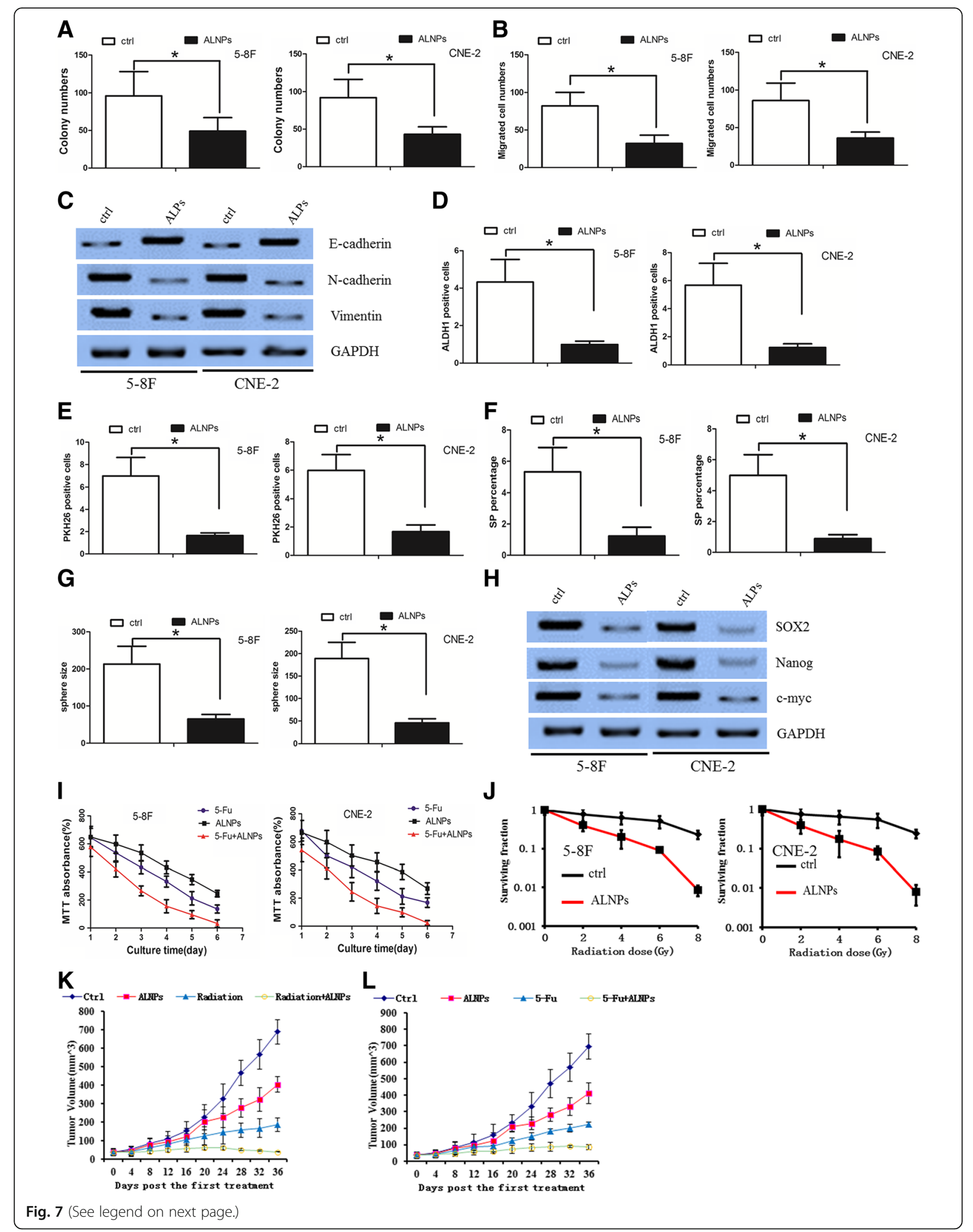


(See figure on previous page.)

Fig. 7 ALNPs exerted an antitumor effect in NPC cells. (a) ALNPs decreased the NPC cell colony formation ability. (b) ALNPs decreased the NPC cell migration ability. (c) ALNPs increased E-cadherin expression but decreased N-cadherin and vimentin expression. (d) ALNPs decreased the ALDH1+ labeling cell rate. (e) ALNPs decreased the PKH26+ labeling cell rate. (f) ALNPs decreased the SP rate. (g) ALNPs decreased the tumor sphere size. (h) ALNPs decreased the CSC-related markers SOX2, Nanog and c-myc. (i) ALNPs increased the NPC cell sensitivity to 5-Fu, as determined by an MTT assay. (j) ALNPs increased the NPC cell sensitivity to radiation, as determined by an MTT assay. (k) ALNPs increased the NPC cell sensitivity to 5-Fu in vivo. (I) ALNPs increased the NPC cell sensitivity to radiation in vivo

demonstrated that EVI1 downregulation decreased the PKH26+ and ALDH1+ cell rate, while overexpression of EVI1 elevated the PKH26+ and ALDH1+ cell rate. In parallel, EVI1 elevated the SP rate and tumor sphere size. The CSC biomarkers c-myc, Nanog and SOX2 were elevated when EVI1 was overexpressed but were decreased when EVI1 was knocked down. We further explored the underlying mechanism of how EVI1 regulated CSC properties. We identified that EVI1 directly bound to the $\beta$-catenin promoter. $\beta$-catenin signaling was important for maintenance of the CSC phenotype. Our previous studies revealed that $\beta$-catenin regulated the CSC properties in a series of cancers, including NPC [32-34]. When binding with cadherin at the membrane, $\beta$-catenin controls cell-cell adhesion. However, when activated by stimulators, $\beta$-catenin acts as a transcriptional activator in the nucleus, where it interacts with LEF1 and TCF transcription factors [52]. Our previous study revealed that nuclear $\beta$-catenin is responsible for the maintenance of CSCs properties [32-34].

Our present data revealed that EVI1 increased the transcriptional activity of the $\beta$-catenin promoter and promoted $\beta$-catenin nuclear translocation in NPC cells. $\beta$-catenin downregulation blocked the effects of EVI1 on CSC properties. In summary, our data confirmed that EVI1 was a functional marker of CSCs and revealed that $\beta$-catenin mediated the function of EVI1 in CSCs.

The EMT phenotype, together with CSCs, contributes to chemo-/radioresistance in cancer [53]. Targeting EMT and CSC maintenance is a promising therapeutic strategy in cancer. Our above findings revealed that downregulation of EVI1 reversed the EMT phenotype and eliminated CSC properties. We further asked whether targeting EVI1 could overcome chemo-/radioresistance in NPC cells. As expected, knockdown of EVI1 increased NPC cell sensitivity to 5-Fu and irradiation. A previous study revealed that Evil defines tyrosine kinase inhibitor resistance in chronic myeloid leukemia [51]. In acute myeloid leukemia, EVI1 decreased the cell sensitivity to daunorubicin [54]. In solid cancer, knockdown of EVI1 restored prostate cancer sensitivity to docetaxel [45]. These findings are parallel with our data.

In our clinical NPC sample analysis, high-level EVI1 expression was correlated with shorter OS and PFS. These data indicated that EVI1 may be an unfavorable prognosis factor in NPC. The association of EVI1 and EMT and CSC-related genes was also demonstrated in NPC tissues, which further confirmed the in vitro study.

ATO can degrade EVI1 protein and is used for the clinical treatment of acute promyelocytic leukemia [55]. In addition, ATO may have a promising therapeutic effect on solid tumors [56]. However, the low water solubility and adverse side effects of ATO [57] restrict the its efficacy in the treatment of solid tumors. Drug delivery systems based on nanotechnology can improve drug efficacy and reduce side effects $[58,59]$. We thus designed HAS-loaded ATO and tested the antitumor effect of this drug system. EVI1 protein was degraded by the ALNP drug system. ALNPs decreased the NPC cell growth and invasion ability effectively. In addition, ALNPs exhibited few side effects in mice, suggesting that HAS-loaded ATO may be effectively and safely used in cancer treatment.

In summary, we demonstrated that EVI1 is elevated in NPC tissues and cell lines. EVI1 may promote the EMT phenotype and CSC properties in NPC cells. EVI1 confers chemo-/radioresistance in NPC cells (wording model as Fig. 8). Treatment with ATO may be an effective option for targeting EVI1 in NPC.

\section{Conclusions}

In conclusion, our study demonstrated that EVI1 was upregulated in NPC tissues and cell lines. EVI1 repressed E-cadherin expression and ultimately contributed to EMT phenotype in NPC cells. $\beta$-catenin mediated EVI1's function on cancer stem cells properties. EVI1 up-regulation predicted unfavorable prognosis and contributed to chemo/radio-resistance in NPC cells. Our findings indicated that EVI1 may be a potential therapeutic target for NPC treatment.

\section{Additional files}

Additional file 1: Figure S1. (A)Volcano plot showing the difference in transcripts between the sh-ctrl and sh-EVI1 group. (B) Circle map showing the distribution patterns of different transcripts in the human genome. (C) GO enrichment analysis of EVI1-regulated mRNAs. (D) A GSEA assay showed that EVI1 might play a role in the AKT and ERK signaling pathway. (TIF $5589 \mathrm{~kb}$ )

Additional file 2: Figure S2. (A) The morphology change of NPC cells which have undergone EMT phenotype(5-8F and CNE-2 cell lines). (B) EVI1 regulated E-cadherin mRNA expression. (C) EVI1-interacting proteins 
were indicated. (D) Nuclear colocalization of EVI1 and snail proteins was clearly detected in NPC cells. (E) The enforced expression and si- $\beta$-catenin were confirmed by western blot assay. (F)- (J) Functional effects on CSCS upon silencing or overexpression of EVI1 were partially rescued by the forced expression of $\beta$-catenin or si- $\beta$-catenin. (K) The expression of EVI1, E-cadherin, N-cadherin, vimentin, SOX2, Nanog and c-myc in NPC tissues as revealed by an IHC assay. (TIF $12346 \mathrm{~kb}$ )

Additional file 3: Figure S4. (A) WNT inhibitor drug Cardamonin (CAS 19309-14-9) decreased cell proliferation in 5-8F, CNE-2 and LV-EVI1-6-10B cells, as revealed by MTT assay. (B) WNT inhibitor drug Cardamonin (CAS 19309-14-9) impaired colony formation ability of 5-8F, CNE-2 and LVEVI1-6-10B cells. (C) The transwell assay revealed that WNT inhibitor drug Cardamonin (CAS 19309-14-9) decreased cell invasion ability of 5-8F, CNE-2 and LV-EVI1-6-10B cells. (D) Wnt agonist drug CAS 853220-52-7 reinforced cell growth, colony formation and invasion ability in sh-EVI1-58F and sh-EVI1-CNE-2 cells. (E) EVI-1 overexpression effect on cell growth, colony formation and invasion ability could be partly counteracted by ATO treatment. (TIF $6304 \mathrm{~kb}$ )

Additional file 4: Figure S3. (A) TEM images revealed that the ALNPS were uniform in size distribution with core-shell nanostructures. (B) The size of ALNPs was approximately $50-60 \mathrm{~nm}$ as determined by DLS. (C) Compared with free ATO, the ALNP drug delivery system significantly elevated the cytotoxicity to NPC cells as revealed by an MTT assay. (D) ALNPs degraded the EVI1 protein in NPC cell lines. (E)-(F) ALNPs have synergistic effects with both 5-Fu and radiation. (G) H\&E staining of tissue sections from the main organs of mice in the PBS- and ALNP-treated groups. (TIF $7703 \mathrm{~kb}$ )

\section{Abbreviations}

ALNPs: arsenic trioxide-loaded nanoparticles; Co-IP: Coimmunoprecipitation CSC: cancer stem cells; EBV: Epstein-Barr virus; EMSA: Electrophoretic mobility shift assay; EMT: epithelial-to-mesenchymal transition; NPC: nasopharyngeal carcinoma; PVDF: polyvinylidene fluoride

\section{Acknowledgements}

Not applicable.

\section{Funding}

This work was supported by the grant from National Natural Science Foundation of China (No. 81502576 and 81502194), the grant from Guangdong Provincial Department of Science and Technology(No. 2015A030313465 and No.2014A030310045), the grant from Guangzhou Municipal Health Bureau(General boot project, No.20151A011091) and Bureau of Education of Guangzhou Municipality (No.1201630115).

\section{Availability of data and materials}

Data sharing not applicable to this article as no datasets were generated or analyzed during the current study.

\section{Authors' contributions}

$Y L$, and $X D$ were responsible for the design of the study. $Y L, X Z$ and $X D$ performed the experiments. GZ and WH collected tissue samples and wrote the first draft of the manuscript. All authors commented on the manuscript and approved the final version.

\section{Ethics approval and consent to participate}

The study on NPC cancer samples was approved and supervised by the Research Ethics Committee of Cancer Center Hospital of Guangzhou Medical University. Written Informed Consents were obtained from all patients. The animal experiments were performed in strict accordance with the guidelines of the Research Animal Care Committee of Cancer Center Hospital of Guangzhou Medical University.

\section{Consent for publication}

Not applicable.

\section{Competing interests}

The authors declare that they have no competing interests.

\section{Publisher's Note}

Springer Nature remains neutral with regard to jurisdictional claims in published maps and institutional affiliations.

\section{Author details}

'Department of Oncology (Section 3), Gaozhou People's Hospital, Gaozhou, Guangdong, China. ${ }^{2}$ Affiliated Cancer Hospital \& Institute of Guangzhou Medical University, Guangzhou, China. ${ }^{3}$ Yanling Hospital of Southern Medical University, Guangzhou, China. ${ }^{4}$ Department of Pharmacy, Maoming People's Hospital, Maoming, Guangdong, China. ${ }^{5}$ Department of Radiotherapy, People's Hospital of Shanxi Province, Taiyuan, China.

Received: 23 October 2018 Accepted: 5 February 2019

Published online: 15 February 2019

\section{References}

1. Jiang Q, Mai C, Yang H, Wu Q, Hua S, Yan C, Long Y, Zhang Y, Long X, Fang $W$, et al. Nuclear expression of CDK4 correlates with disease progression and poor prognosis in human nasopharyngeal carcinoma. Histopathology. 2014;64(5):722-30.

2. Zhen Y, Liu Z, Yang H, Yu X, Wu Q, Hua S, Long X, Jiang Q, Song Y, Cheng $C$, et al. Tumor suppressor PDCD4 modulates miR-184-mediated direct suppression of C-MYC and BCL2 blocking cell growth and survival in nasopharyngeal carcinoma. Cell Death Dis. 2013;4:e872.

3. Hu Z, Hu S, Ji C, Tang Z, Thakral B, Loghavi S, Medeiros LJ, Wang W. 3q26/ EVI1 rearrangement in myelodysplastic/myeloproliferative neoplasms: an early event associated with a poor prognosis. Leuk Res. 2018;65:25-8.

4. Wang $H$, Schaefer T, Konantz M, Braun M, Varga Z, Paczulla AM, Reich S, Jacob F, Perner S, Moch H, et al. Prominent oncogenic roles of EVI1 in breast carcinoma. Cancer Res. 2017;77(8):2148-60.

5. Sayadi A, Jeyakani J, Seet SH, Wei CL, Bourque G, Bard FA, Jenkins NA, Copeland NG, Bard-Chapeau EA. Functional features of EVI1 and EVI1Delta324 isoforms of MECOM gene in genome-wide transcription regulation and oncogenicity. Oncogene. 2016;35(18):2311-21.

6. Tanaka M, Suzuki HI, Shibahara J, Kunita A, Isagawa T, Yoshimi A, Kurokawa M, Miyazono K, Aburatani H, Ishikawa S, et al. EVI1 oncogene promotes KRAS pathway through suppression of microRNA-96 in pancreatic carcinogenesis. Oncogene. 2014;33(19):2454-63.

7. Vincent-Salomon A, Thiery JP. Host microenvironment in breast cancer development: epithelial-mesenchymal transition in breast cancer development. Breast cancer research : BCR. 2003:5(2):101-6.

8. Onder TT, Gupta PB, Mani SA, Yang J, Lander ES, Weinberg RA. Loss of Ecadherin promotes metastasis via multiple downstream transcriptional pathways. Cancer Res. 2008;68(10):3645-54.

9. Haraguchi M, Okubo T, Miyashita Y, Miyamoto Y, Hayashi M, Crotti TN, McHugh KP, Ozawa M. Snail regulates cell-matrix adhesion by regulation of the expression of integrins and basement membrane proteins. J Biol Chem. 2008;283(35):23514-23.

10. Herranz N, Pasini D, Diaz VM, Franci C, Gutierrez A, Dave N, Escriva M, Hernandez-Munoz I, Di Croce L, Helin K, et al. Polycomb complex 2 is required for E-cadherin repression by the Snail1 transcription factor. Mol Cell Biol. 2008;28(15):4772-81.

11. Floor S, van Staveren WC, Larsimont D, Dumont JE, Maenhaut C. Cancer cells in epithelial-to-mesenchymal transition and tumor-propagating-cancer stem cells: distinct, overlapping or same populations. Oncogene. 2011; 30(46):4609-21.

12. Kong D, Li Y, Wang Z, Sarkar FH. Cancer stem cells and epithelial-tomesenchymal transition (EMT)-phenotypic cells: are they cousins or twins? Cancers. 2011;3(1):716-29.

13. Ricardo S, Vieira AF, Gerhard R, Leitao D, Pinto R, Cameselle-Teijeiro JF, Milanezi F, Schmitt F, Paredes J. Breast cancer stem cell markers CD44, CD24 and ALDH1: expression distribution within intrinsic molecular subtype. J Clin Pathol. 2011;64(11):937-46.

14. Wu A, Luo W, Zhang Q, Yang Z, Zhang G, Li S, Yao K. Aldehyde dehydrogenase 1, a functional marker for identifying cancer stem cells in human nasopharyngeal carcinoma. Cancer Lett. 2013;330(2):181-9.

15. Wang WJ, Wu SP, Liu JB, Shi YS, Huang X, Zhang QB, Yao KT. MYC regulation of $\mathrm{CHK} 1$ and $\mathrm{CHK} 2$ promotes radioresistance in a stem cell-like population of nasopharyngeal carcinoma cells. Cancer Res. 2013;73(3):1219-31. 
16. Takebe N, Warren RQ, Ivy SP. Breast cancer growth and metastasis: interplay between cancer stem cells, embryonic signaling pathways and epithelial-tomesenchymal transition. Breast cancer research : BCR. 2011;13(3):211.

17. Vinogradov $S$, Wei $X$. Cancer stem cells and drug resistance: the potential of nanomedicine. Nanomedicine. 2012;7(4):597-615.

18. Donnenberg VS, Donnenberg AD. Multiple drug resistance in cancer revisited: the cancer stem cell hypothesis. J Clin Pharmacol. 2005;45(8):872-7.

19. Spratt DE, Lee N. Current and emerging treatment options for nasopharyngeal carcinoma. OncoTargets and therapy. 2012;5:297-308.

20. Deng XB, Xiao L, Wu Y, Jin F, Mossman B, Testa JR, Xiao GH. Inhibition of mesothelioma cancer stem-like cells with adenovirus-mediated NK4 gene therapy. Int J Cancer. 2015;137(2):481-90.

21. Luo W, Li S, Peng B, Ye Y, Deng X, Yao K. Embryonic stem cells markers SOX2 OCT4 and Nanog expression and their correlations with epithelial-mesenchymal transition in nasopharyngeal carcinoma. PLoS One. 2013;8(2):e56324.

22. Li K, Zhou ZY, Ji PP, Luo HS. Knockdown of beta-catenin by siRNA influences proliferation, apoptosis and invasion of the colon cancer cell line SW480. Oncol Lett. 2016;11(6):3896-900

23. Bard-Chapeau EA, Jeyakani J, Kok CH, Muller J, Chua BQ, Gunaratne J, Batagov A, Jenjaroenpun P, Kuznetsov VA, Wei CL, et al. Ecotopic viral integration site 1 (EVI) regulates multiple cellular processes important for cancer and is a synergistic partner for FOS protein in invasive tumors. Proc Natl Acad Sci U S A. 2012;109(6):2168-73.

24. Miao X, Gao H, Liu S, Chen M, Xu W, Ling X, Deng X, Rao C. Downregulation of microRNA-224 -inhibites growth and epithelial-tomesenchymal transition phenotype -via modulating SUFU expression in bladder cancer cells. Int J Biol Macromol. 2018;106:234-40.

25. Peng Y, Zhao Z, Liu T, Li X, Hu X, Wei X, Zhang X, Tan W. Smart humanserum-albumin-As2 $\mathrm{O} 3$ Nanodrug with self-amplified folate receptortargeting ability for chronic myeloid leukemia treatment. Angew Chem. 2017:56(36):10845-9.

26. Chi X, Yin Z, Jin J, Li H, Zhou J, Zhao Z, Zhang S, Zhao W, Xie C, Li J, et al. Arsenite-loaded nanoparticles inhibit the invasion and metastasis of a hepatocellular carcinoma: in vitro and in vivo study. Nanotechnology. 2017; 28(44):445101

27. Zhao X, He L, Li T, Lu Y, Miao Y, Liang S, Guo H, Bai M, Xie H, Luo G, et al. SRF expedites metastasis and modulates the epithelial to mesenchymal transition by regulating miR-199a-5p expression in human gastric cancer. Cell Death Differ. 2014;21(12):1900-13.

28. Wakahashi S, Sudo T, Oka N, Ueno S, Yamaguchi S, Fujiwara K, Ohbayashi C, Nishimura R. VAV1 represses E-cadherin expression through the transactivation of snail and slug: a potential mechanism for aberrant epithelial to mesenchymal transition in human epithelial ovarian cancer. Translational research : the journal of laboratory and clinical medicine. 2013; 162(3):181-90.

29. Chen Z, Liu M, Liu X, Huang S, Li L, Song B, Li H, Ren Q, Hu Z, Zhou Y, et al. COX-2 regulates $E$-cadherin expression through the $\mathrm{NF}$-kappaB/snail signaling pathway in gastric cancer. Int J Mol Med. 2013;32(1):93-100.

30. Arzumanyan A, Friedman T, Kotei E, Ng IO, Lian Z, Feitelson MA. Epigenetic repression of $\mathrm{E}$-cadherin expression by hepatitis $\mathrm{B}$ virus $\mathrm{x}$ antigen in liver cancer. Oncogene. 2012;31(5):563-72.

31. Qin J, Ji J, Deng R, Tang J, Yang F, Feng GK, Chen WD, Wu XQ, Qian XJ, Ding K, et al. DC120, a novel AKT inhibitor, preferentially suppresses nasopharyngeal carcinoma cancer stem-like cells by downregulating Sox2. Oncotarget. 2015;6(9):6944-58.

32. Ma L, Zhang G, Miao XB, Deng XB, Wu Y, Liu Y, Jin ZR, Li XQ, Liu QZ, Sun DX, et al. Cancer stem-like cell properties are regulated by EGFR/AKT/betacatenin signaling and preferentially inhibited by gefitinib in nasopharyngeal carcinoma. FEBS J. 2013:280(9):2027-41.

33. Zhang G, Wang W, Yao C, Zhang S, Liang L, Han M, Ren J, Qi X, Zhang X, Wang $S$, et al. Radiation-resistant cancer stem-like cell properties are regulated by PTEN through the activity of nuclear beta-catenin in nasopharyngeal carcinoma. Oncotarget. 2017;8(43):74661-72.

34. Li XQ, Yang XL, Zhang G, Wu SP, Deng XB, Xiao SJ, Liu QZ, Yao KT, Xiao GH. Nuclear beta-catenin accumulation is associated with increased expression of Nanog protein and predicts poor prognosis of non-small cell lung cancer. J Transl Med. 2013;11:114.

35. Kustikova OS, Schwarzer A, Stahlhut M, Brugman MH, Neumann T, Yang M, Li Z, Schambach A, Heinz N, Gerdes S, et al. Activation of Evi1 inhibits cell cycle progression and differentiation of hematopoietic progenitor cells. Leukemia. 2013;27(5):1127-38.
36. Nayak KB, Sajitha IS, Kumar TRS, Chakraborty S. Ecotropic viral integration site 1 promotes metastasis independent of epithelial mesenchymal transition in colon cancer cells. Cell Death Dis. 2018;9(2):18.

37. Tanaka M, Ishikawa S, Ushiku T, Morikawa T, Isagawa T, Yamagishi M, Yamamoto H, Katoh H, Takeshita K, Arita J, et al. EVI1 modulates oncogenic role of GPC1 in pancreatic carcinogenesis. Oncotarget. 2017;8(59):99552-66.

38. Maicas M, Vazquez I, Alis R, Marcotegui N, Urquiza L, Cortes-Lavaud X, Cristobal I, Garcia-Sanchez MA, Odero MD. The MDS and EVI1 complex locus (MECOM) isoforms regulate their own transcription and have different roles in the transformation of hematopoietic stem and progenitor cells. Biochim Biophys Acta. 2017;1860(6):721-9.

39. Tjia WM, Sham JS, Hu L, Tai AL, Guan XY. Characterization of $3 p, 5 p$, and $3 q$ in two nasopharyngeal carcinoma cell lines, using region-specific multiplex fluorescence in situ hybridization probes. Cancer Genet Cytogenet. 2005; 158(1):61-6

40. Bei JX, Li Y, Jia WH, Feng BJ, Zhou G, Chen LZ, Feng QS, Low HQ, Zhang H, He $F$, et al. A genome-wide association study of nasopharyngeal carcinoma identifies three new susceptibility loci. Nat Genet. 2010;42(7):599-603.

41. Wieser R. The oncogene and developmental regulator EVI1: expression, biochemical properties, and biological functions. Gene. 2007;396(2):346-57.

42. Nanjundan M, Nakayama Y, Cheng KW, Lahad J, Liu J, Lu K, Kuo WL, SmithMcCune K, Fishman D, Gray JW, et al. Amplification of MDS1/EVI1 and EVI1, located in the 3q26.2 amplicon, is associated with favorable patient prognosis in ovarian cancer. Cancer Res. 2007;67(7):3074-84.

43. Gao JS, Zhang Y, Tang X, Tucker LD, Tarwater PM, Quesenberry PJ, Rigoutsos I, Ramratnam B. The Evi1, microRNA-143, K-Ras axis in colon cancer. FEBS Lett. 2011;585(4):693-9.

44. Jazaeri AA, Ferriss JS, Bryant JL, Dalton MS, Dutta A. Evaluation of EVI1 and EVI1s (Delta324) as potential therapeutic targets in ovarian cancer. Gynecol Oncol. 2010;118(2):189-95.

45. Queisser A, Hagedorn S, Wang H, Schaefer T, Konantz M, Alavi S, Deng M, Vogel W, von Massenhausen A, Kristiansen G, et al. Ecotropic viral integration site 1, a novel oncogene in prostate cancer. Oncogene. 2017; 36(11):1573-84.

46. Dutta P, Bui T, Bauckman KA, Keyomarsi K, Mills GB, Nanjundan M. EVI1 splice variants modulate functional responses in ovarian cancer cells. Mol Oncol. 2013;7(3):647-68.

47. Nie D, Shan X, Nie L, Duan Y, Chen Z, Yang Y, Li Z, Tian L, Gao Q, Shan Y, et al. Hepatitis $C$ virus core protein interacts with snail and histone deacetylases to promote the metastasis of hepatocellular carcinoma. Oncogene. 2016;35(28):3626-35.

48. Tong ZT, Cai MY, Wang XG, Kong LL, Mai SJ, Liu YH, Zhang HB, Liao YJ, Zheng F, Zhu W, et al. EZH2 supports nasopharyngeal carcinoma cell aggressiveness by forming a co-repressor complex with HDAC1/HDAC2 and snail to inhibit E-cadherin. Oncogene. 2012;31(5):583-94.

49. Yoshimi A, Goyama S, Watanabe-Okochi N, Yoshiki Y, Nannya Y, Nitta E, Arai S, Sato T, Shimabe M, Nakagawa M, et al. Evi1 represses PTEN expression and activates PI3K/AKT/mTOR via interactions with polycomb proteins. Blood 2011:117(13):3617-28.

50. Bessede E, Staedel C, Acuna Amador LA, Nguyen PH, Chambonnier L, Hatakeyama M, Belleannee G, Megraud F, Varon C. Helicobacter pylori generates cells with cancer stem cell properties via epithelial-mesenchymal transition-like changes. Oncogene. 2014:33(32):4123-31.

51. Sato T, Goyama S, Kataoka K, Nasu R, Tsuruta-Kishino T, Kagoya Y, Nukina A, Kumagai K, Kubota N, Nakagawa M, et al. Evi1 defines leukemia-initiating capacity and tyrosine kinase inhibitor resistance in chronic myeloid leukemia. Oncogene. 2014;33(42):5028-38.

52. Mei XD, Su H, Song J, Dong L. Prognostic significance of beta-catenin expression in patients with non-small cell lung cancer: a meta-analysis. Bioscience trends. 2013:7(1):42-9.

53. Singh A, Settleman J. EMT, cancer stem cells and drug resistance: an emerging axis of evil in the war on cancer. Oncogene. 2010;29(34):4741-51.

54. Rommer A, Steinmetz B, Herbst F, Hackl H, Heffeter P, Heilos D, Filipits M, Steinleitner K, Hemmati S, Herbacek I, et al. EVI1 inhibits apoptosis induced by antileukemic drugs via upregulation of CDKN1A/p21/WAF in human myeloid cells. PLoS One. 2013;8(2):e56308.

55. Wang $Z Y, C$ hen $Z$. Acute promyelocytic leukemia: from highly fatal to highly curable. Blood. 2008;111(5):2505-15.

56. Murgo AJ. Clinical trials of arsenic trioxide in hematologic and solid tumors: overview of the National Cancer Institute cooperative Research and Development studies. Oncologist. 2001;6(Suppl 2):22-8. 
57. Dilda PJ, Hogg PJ. Arsenical-based cancer drugs. Cancer Treat Rev. 2007 33(6):542-64.

58. Chi X, Huang D, Zhao Z, Zhou Z, Yin Z, Gao J. Nanoprobes for in vitro diagnostics of cancer and infectious diseases. Biomaterials. 2012;33(1):189-206.

59. Wong PT, Choi SK. Mechanisms of drug release in nanotherapeutic delivery systems. Chem Rev. 2015;115(9):3388-432.

Ready to submit your research? Choose BMC and benefit from:

- fast, convenient online submission

- thorough peer review by experienced researchers in your field

- rapid publication on acceptance

- support for research data, including large and complex data types

- gold Open Access which fosters wider collaboration and increased citations

- maximum visibility for your research: over $100 \mathrm{M}$ website views per year

At $B M C$, research is always in progress.

Learn more biomedcentral.com/submissions 